\title{
معالم بِرّهشى
}

\section{مقايسه تاثير دو روش سخنرانى و آموزش جند رسانه اي بر يادتيرى اصول و فنون يرستارى دانشجويان يرستارى}

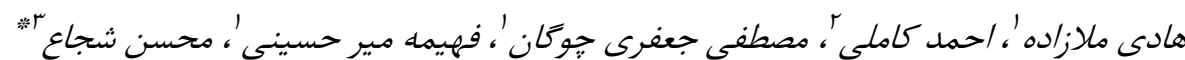

' دانشجوى كارشناسى يرستارى، دانشكده يرستارى اسفراين، دانشخاه علوم يزشكى خراسان شمالى، بجنورد، ايران

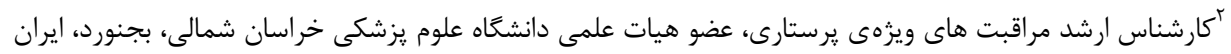

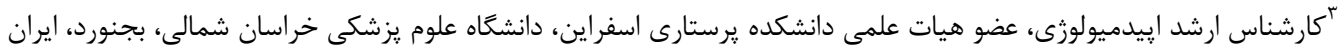

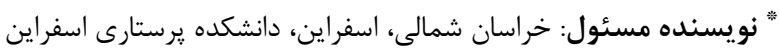
يست الكترونيك: mohsenshoja61@yahoo.com

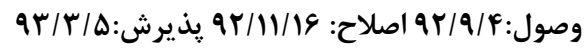

جـكيده

زمينه و هدف: ضرورت /ستفاده /ز روشهاى مناسب آموزشى جهت /رتقاى يادكيرى و مهارتهاى برستارى با توجه به نقش حساس

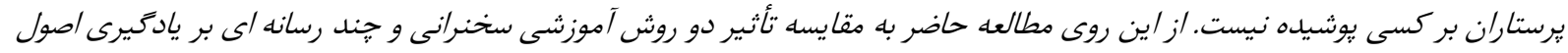

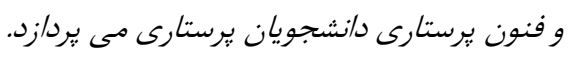

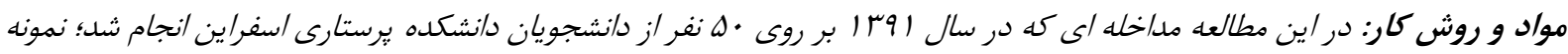

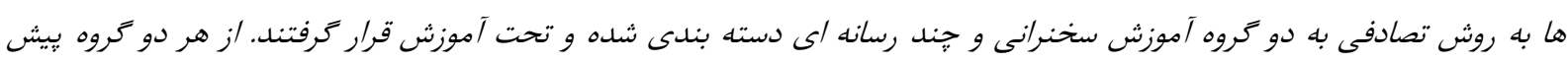

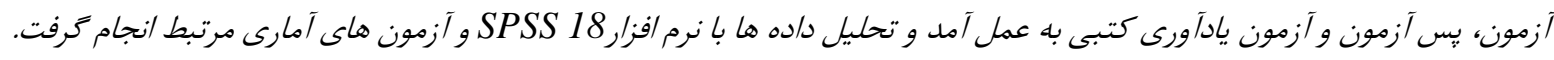

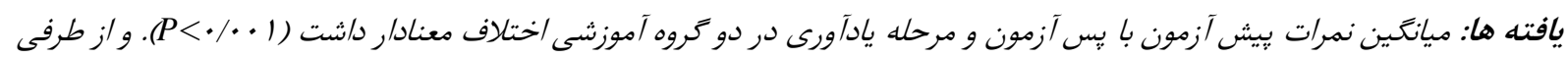

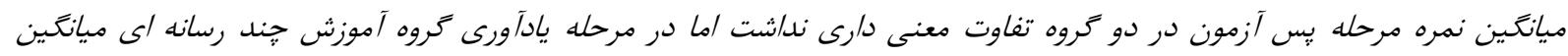

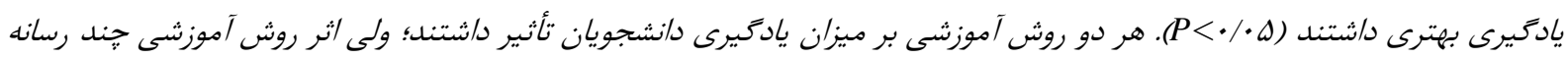

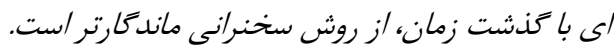

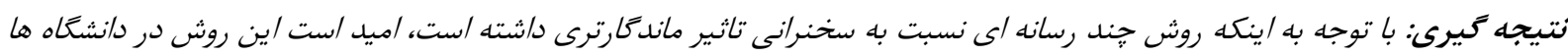

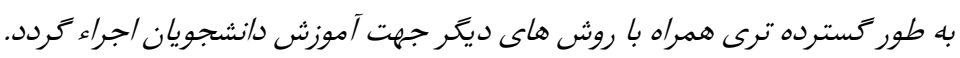

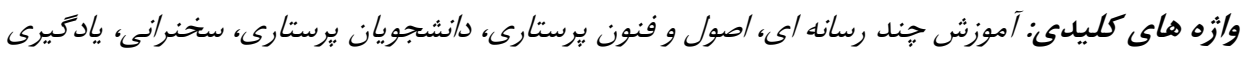

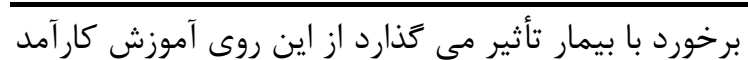

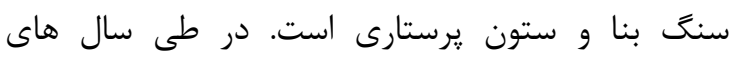

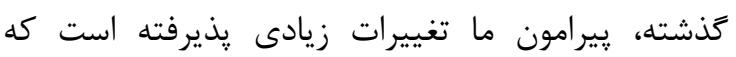

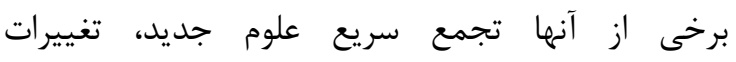
تكنولوزيكى و اكتشافات علمى كسترده است. اين تغييرات

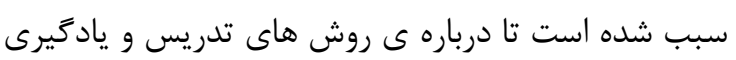

$$
\text { بيشتر تامل شود [1]. }
$$

براى تربيت يك يرستار كارآزموده، با تجربه و مطمئن نياز

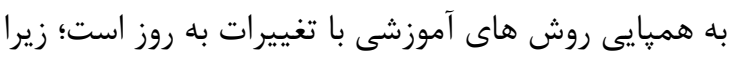

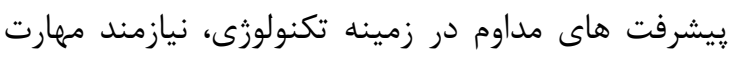

\section{مقدمه}

امروزه ارزش يرستار خوب هم تراز يك يزشك خوب قرار

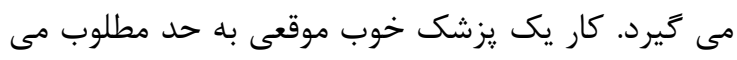

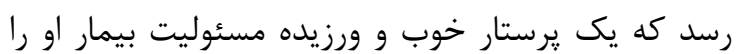
بر عهده داشته باشد. اما تربيت يك يرستار خوب و ورزيده

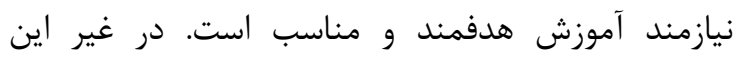
صورت افرادى غير كارآمد تربيت شده كه هم هزئن هزينه زيادى براى آموزش آنها به كشور تحميل شده ور هم هم اين

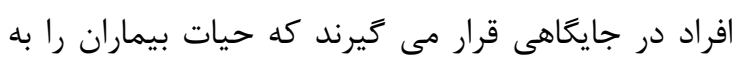

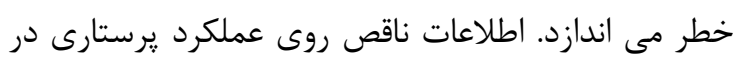


پاسخ دهد [ع1]. اما با توجه به اين كه هنوز از روش هاى آموزشى سنتى و تك محور استفاده مى شود، نياز است كه نظام آموزشى روش هاى خود را به كونه ایى كه دانشجويان

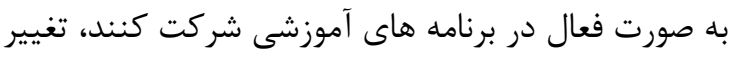
دهد؛ لذا روش هايى همجون حل مسئله، جند رسانه ایى و

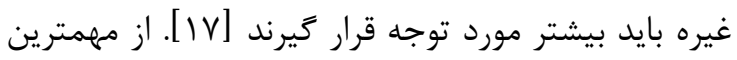

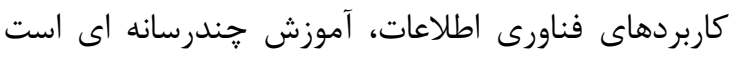

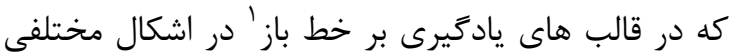

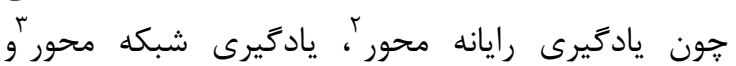

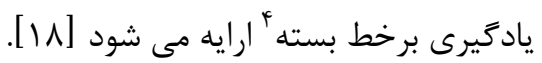

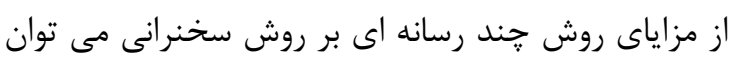

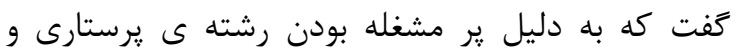
افزونى كار عملى دانشجويان برستارى، تشكيل كلاس هاى برى بردي

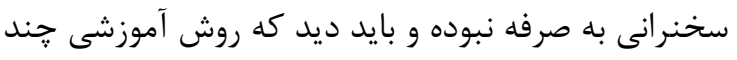
رسانه اى تا ته اندازه مى تواند بهره ورى داند دانشجويان يرستارى را افزايش دهد. با مرورى بر مطالعات مشخص مى شود كه نتايج مطالعات

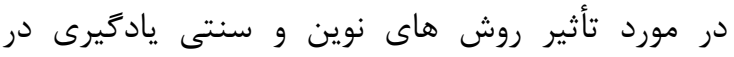

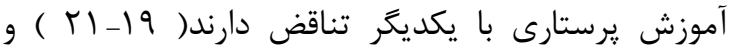

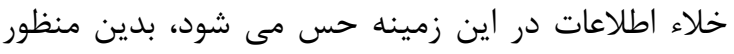

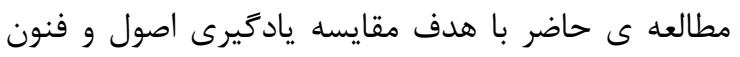
يرستارى در دو روش آموزش به شيوه ى سخنرانى و نرم

افزار קند رسانه اي در دانشجويان يرستارى انجام شد.

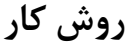

اين مطالعه از نوع مداخله اى است كه در سال |وسا در

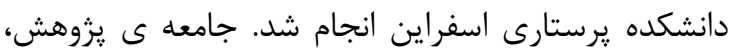
دانشجويان برستارى مقطع كارشناسى دانشكده برستارى

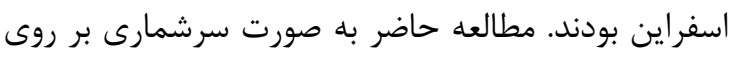

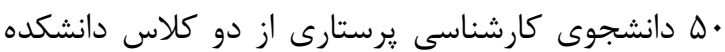
يرستارى اسفراين انجام شد كه اين افراد به دو زير گروها داري

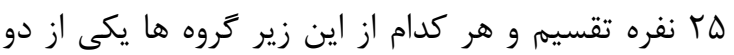

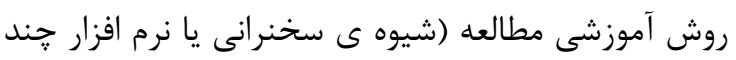
رسانه اى) را به طور تصادفى ساده دريافت كردند. معيار

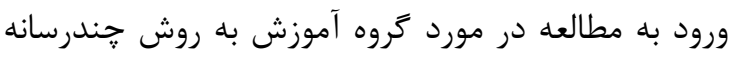

1-On Line Learning

2- Computer- Based Learning

3 -Web-Based Learning 4-Web-Based Learning
هايى مانند حل مسأله و توانايى جهت تصميم گيرى

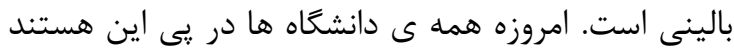

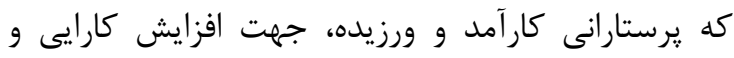

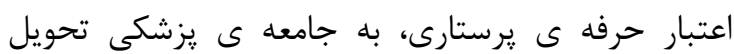

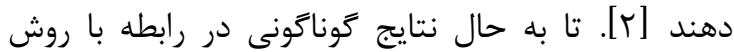

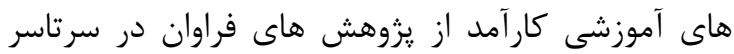

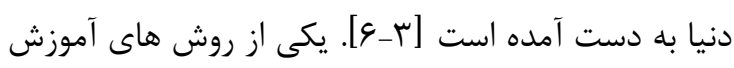

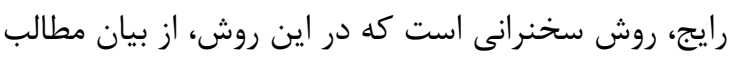

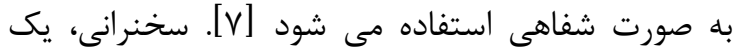
روش سريع، ساده و ارزان در ارائه مى مطالب است. امروزه

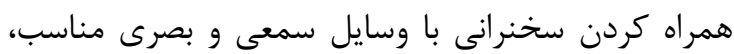
موجب افزايش كارايى اين روش شده است. در هر حال

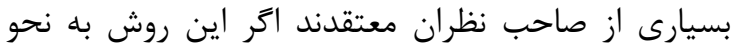

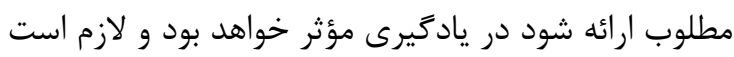

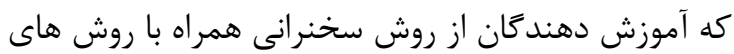

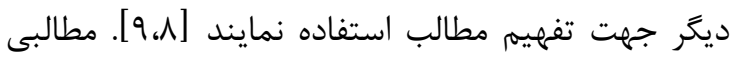

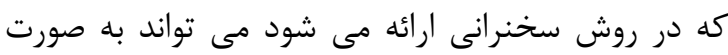

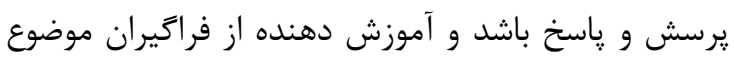

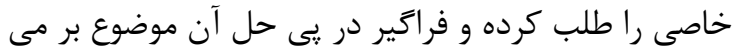

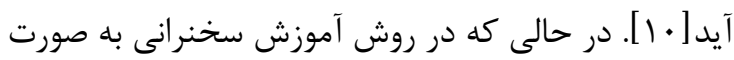

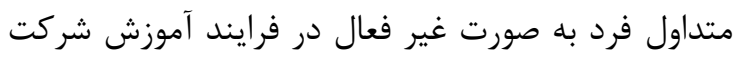

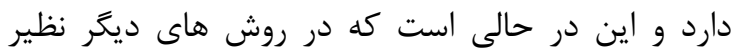

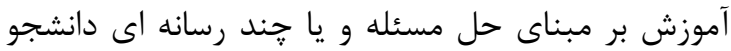
فرصت ييدا مى كند تا به صورت فعال در موضوع مورد

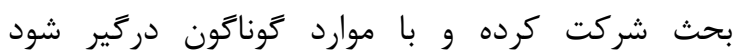

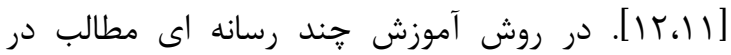

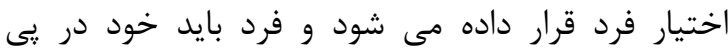

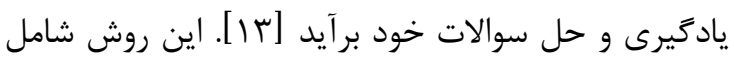
فعاليت هايى است كه فرد مى تواند به صورت انفرادى و

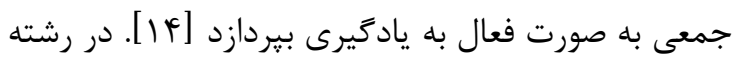
يرستارى، با وجود افزايش امكانات رسانه اى به به ميزان

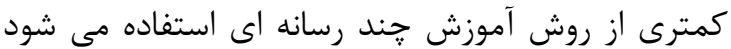

نظام آموزش در عمليات تغيير و تبديل خويش، بايد روش

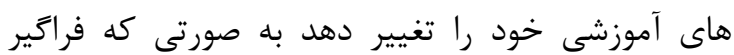

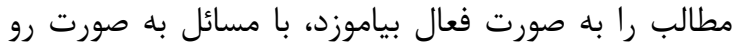
در رو درگير شود و به صورت حل مسئله به مشكلات 
دانشجويان را ياسخ مى داد. در اين روش از ياوريوينت و

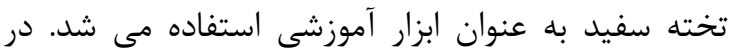

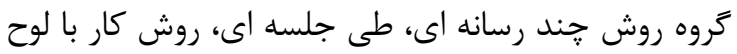

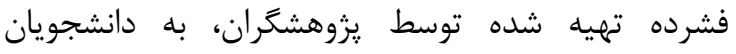
آموزش داده شد؛ و از مهارت آنها در استفاده از اين لوح فشرده، اطمينان حاصل شد. سيس جلساتى در اتاق رايانه

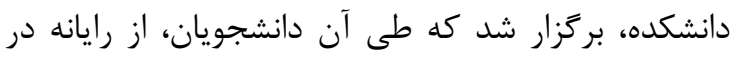

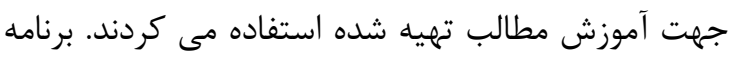

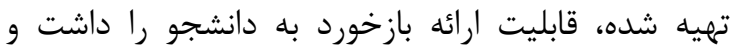
شامل منابع مرتبط و تصاوير و توضيحات صوتى لازم بود.

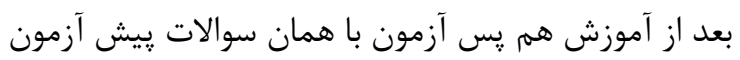

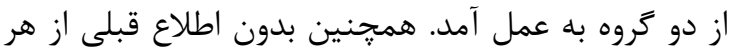

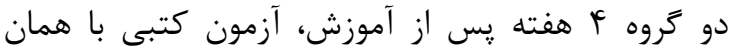

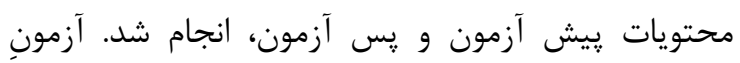

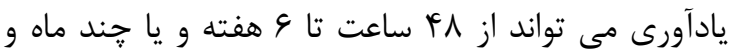

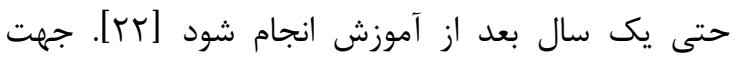

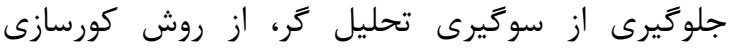

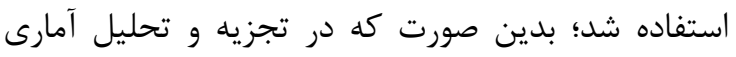
نمرات مربوط به كروه هاى مختلف، كد كروه ها براى تحليل كر ناشناخته بود.

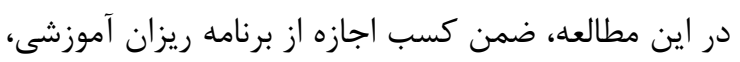
از كليه نمونه ها جهت شركت در مطالعه، رضايت نامه اخذ إندان شد؛ و به آنها اطمينان داده شد كه در هر زمان مختار به به دمان

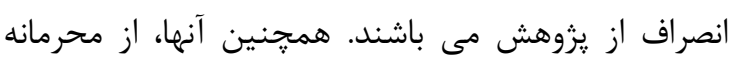
بودن اطلاعات مطمئن شدند. در اين مطالعه تجزيه و تحليل داده ها با استفاده از نرم

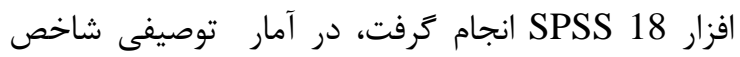
هاى مركزى و يراكندگى و در آمار استنباطى آزمونهاى تى آنى

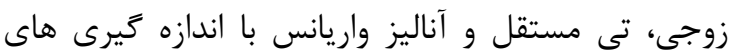
تكرارى مورد استفاده قرار كرفت.

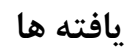

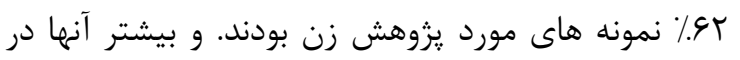

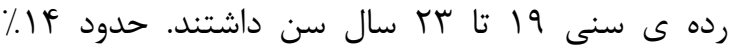
نمونه هاى مورد مطالعه متاهل بودند و هاء از از نمونه هاى

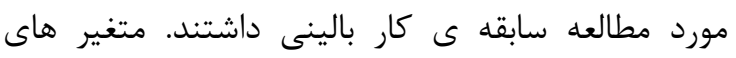
دموكرافيك ارزيابى شده در مطالعه نظير جنسيت، تاهل و

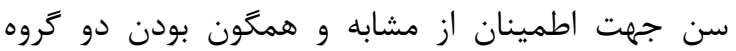

اى، داشتن حداقل آشنايى با كامييوتر و نحوه ى استفاده از لوح فشرده ى جند رسانه اي آموزشى بود و معيار خروج خاصى براى مطالعه وجود نداشت. آموزش ها شامل

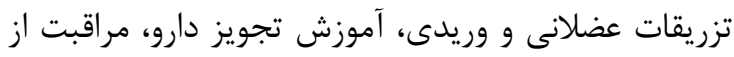
بيمار، مراقبت از حشم، كوش و بينى، نحوه

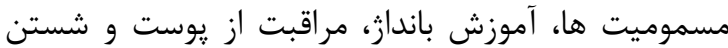
دست به روش جراحى بود، كه توسط اساتيد دروس اصول

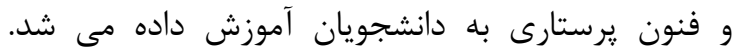
همجنين مطالب آموزش داده شده در هر دو كروه يكسان بود و فقط روش آموزش آنها تفاوت داشت.

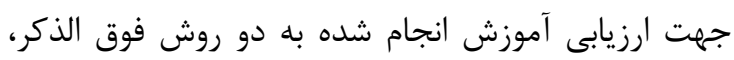
ابتدا سؤالاتى توسط گروه تحقيق از طريق مقالات و منابع إنام

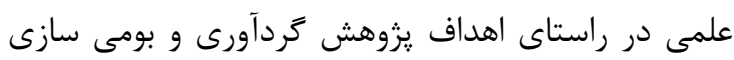

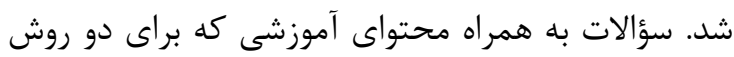
سخنرانى و جند رسانه اى به صورت كاملا يكسان تهيه

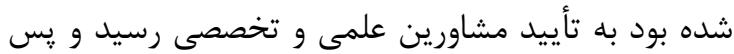

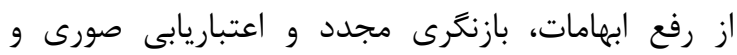

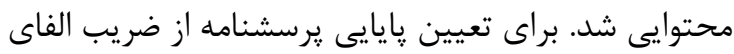

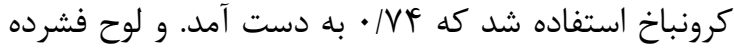

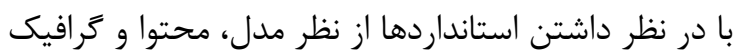

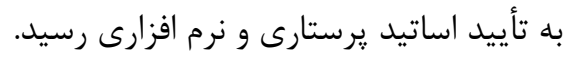

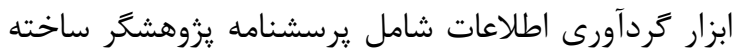
بود كه شامل هif سؤال در هشت موضوع (هر موضوع بين

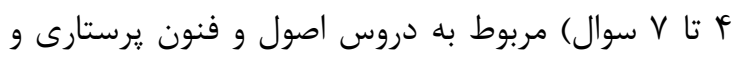

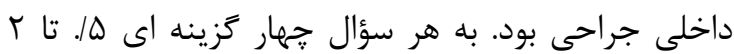
نمره بر حسب دشوارى سؤال تخصيص داده شد. در آدرال

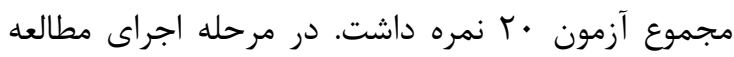

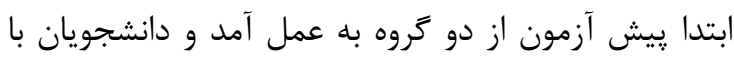
توجه به گروه خود تحت آموزش حضورى به مدت

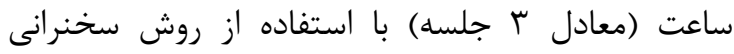

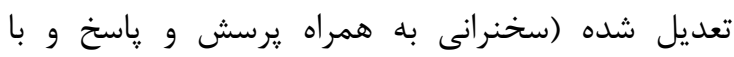

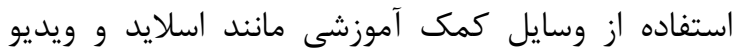

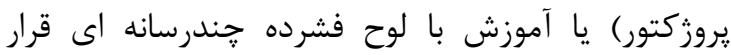

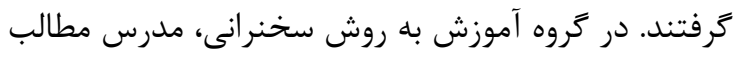

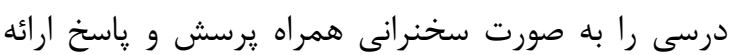

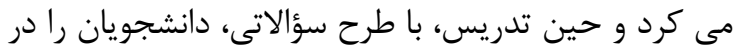

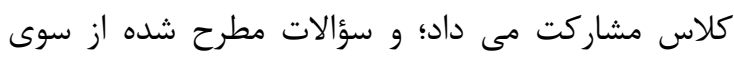




\begin{tabular}{|c|c|c|c|}
\hline 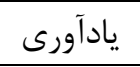 & بعد & 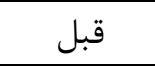 & 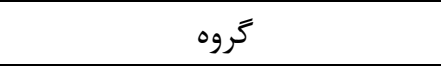 \\
\hline$V / \Gamma$ & $11 / 1$ & $F / T$ & آموزش سخنرانى \\
\hline$\Lambda / V$ & $1 \cdot 11$ & $f / 1$ & آموزش به شيوه خند رسانه اى \\
\hline$p<\cdot / \cdot \Delta$ & $p>\cdot / \cdot \Delta$ & $p>\cdot / \cdot \Delta$ & P- Value(آزمون تى مستقل) \\
\hline
\end{tabular}

جدول ז: مقايسه ى ميانگين نمرات دانشجويان در مرحله قبل از آموزش با بعد از آموزش

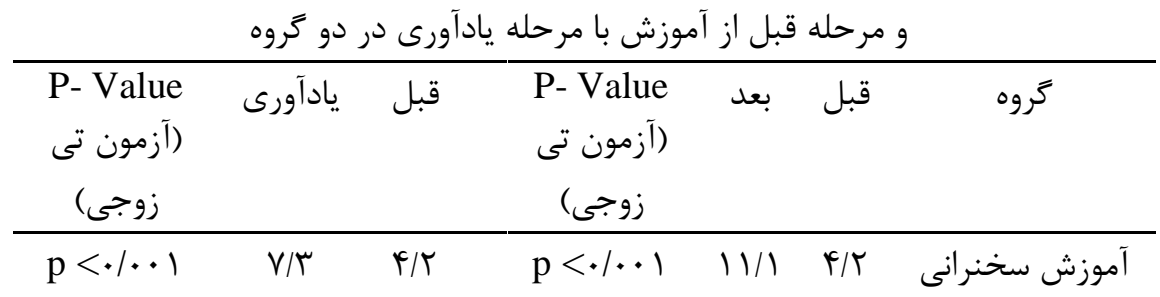

\begin{tabular}{|c|c|c|c|c|c|}
\hline$p<+/ . .1$ & N/V & $F / l$ & $p<\cdot / . .1$ & $1 . / 1 \quad F / 1$ & آموزش به شند رسانه اى \\
\hline
\end{tabular}

\begin{tabular}{|c|c|c|c|c|}
\hline $\begin{array}{c}\text { p- value } \\
\text { آزمون آناليز واريانس بازه كيرى تكرارى) } \\
\end{array}$ & يادآورى & بعد & قبل & 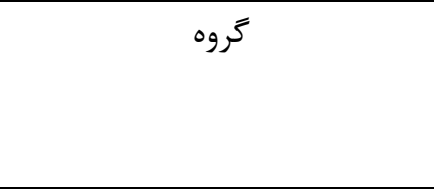 \\
\hline$p<\cdot 1 \cdot \cdot 1$ & $V / T$ & $11 / 1$ & $f / r$ & آموزش سخنرانى \\
\hline $\mathrm{p}<\cdot / \cdot \cdot 1$ & $\Lambda / V$ & $1 \cdot 11$ & $4 / 1$ & آموزش به شيوه ى جند رسانه اى \\
\hline
\end{tabular}




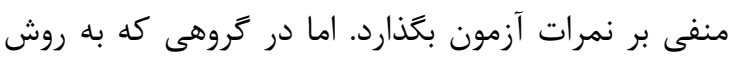

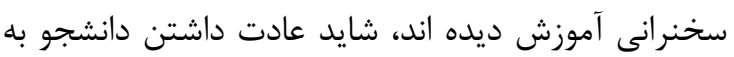

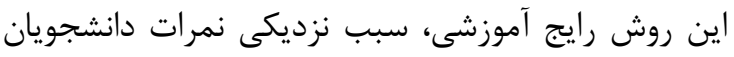

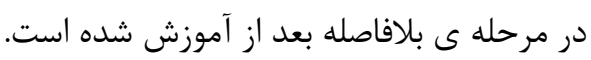
در همسويى با نتايج مطالعه حاضر مى توان به مطالعه

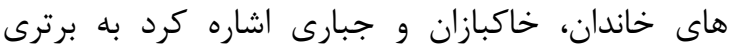

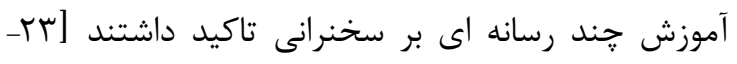

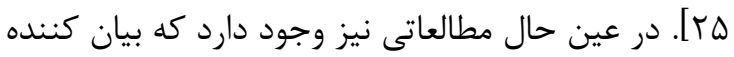

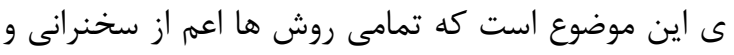

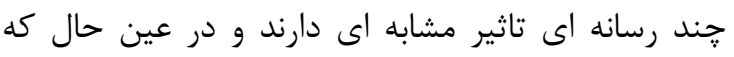

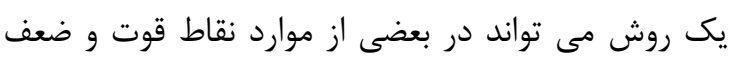

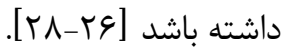

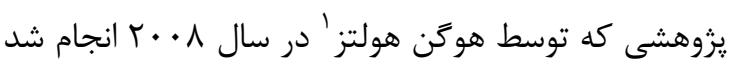
نشان دهنده ى اين موضوع بود كه بين انواع روش هو هاى

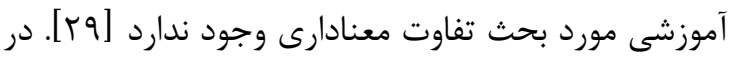
يزوهشى ديكر نتايج نشان داد كه در روش آموزش هند

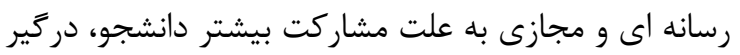

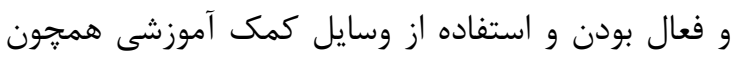

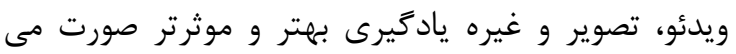

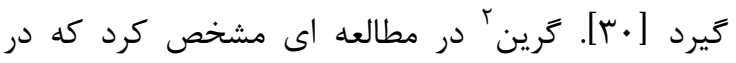

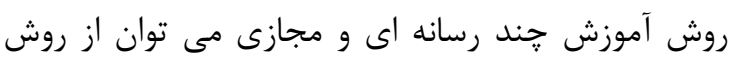

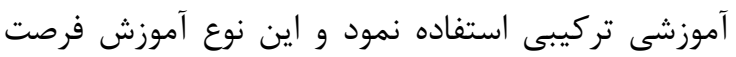
خوبى را براى آموزش مبتنى بر هدئفاده نمد ايت ايت فراهم آموز مي فر آورد

.[r.]

در مطالعه اي آكاروالَّ نشان داد كه دانشجويان، روش

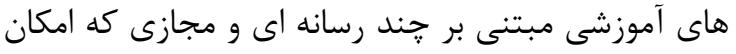

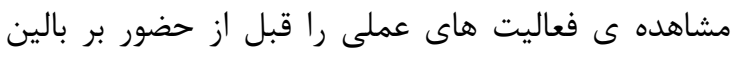

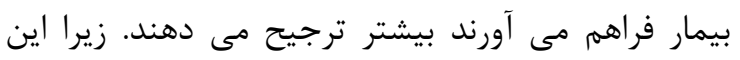

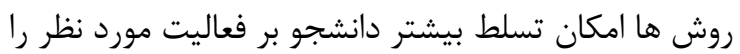

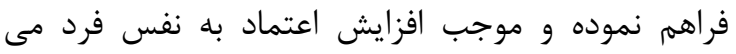

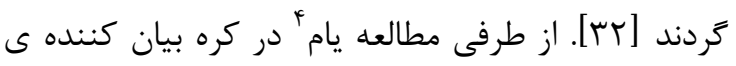

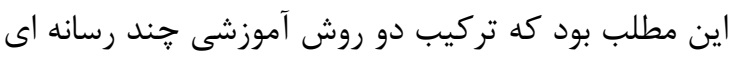

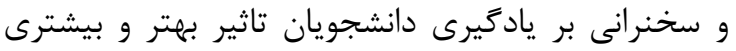

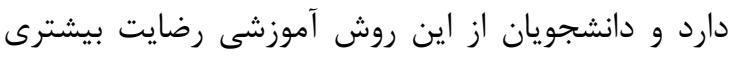

\section{1-Hugenholtz}

2 -Green

3 -Aggarwal

4-Yom
اندازه گيرى شده و در دو گروه اختلاف معنى دار آمارى

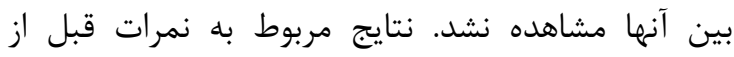

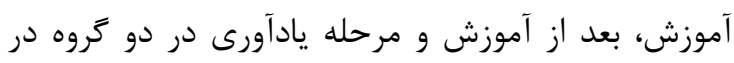

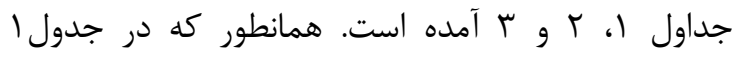
مشاهده مى نمايد نمرات دانشجويان در روش سخنرانى در مرحله ى بعد از آموزش بهتر بوده است ولى در مرحله

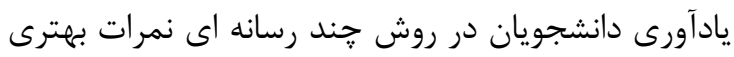

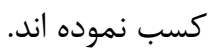
آزمون آمارى تى مستقل نشان داد كه تفاوت معنادارى آنداري

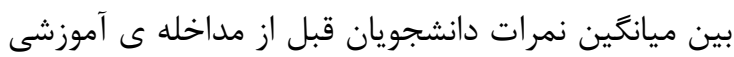

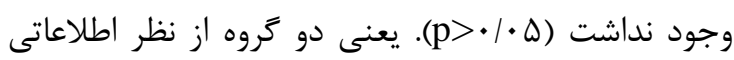

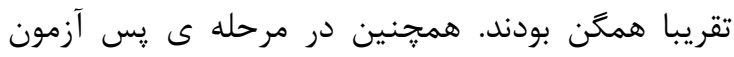

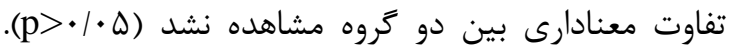

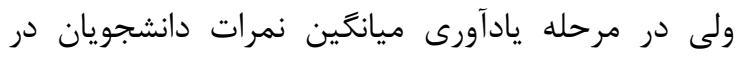

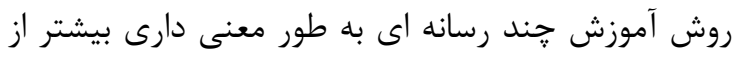

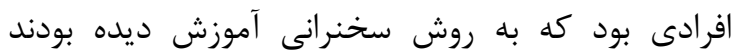

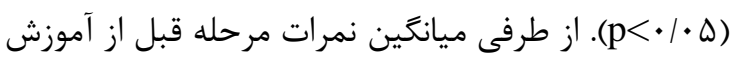

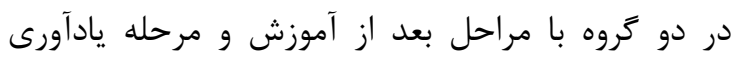
اختلاف معنى دار آمارى داشت (جدول كا). نتايج تحليل

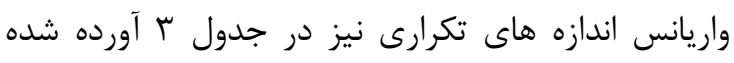

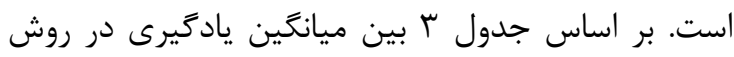
هاى مختلف آموزشى در طول زمان اختلاف معنادار آمارى بدى بـادي وجود داشت. و همانطور كه از ميانكين نمرات آنها

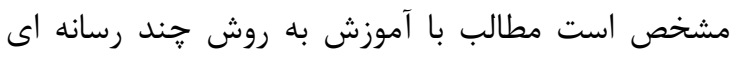
بهتر در حافظه ى بلند مدت دانشجويان مى ماند.

بحث با توجه به يافته هاى اين يزوهش، ميزان يادگيرى در

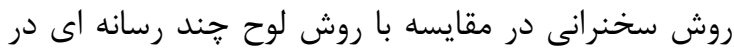

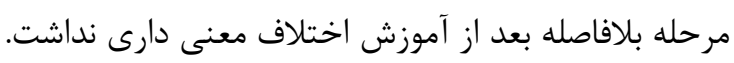

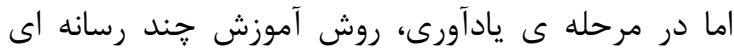

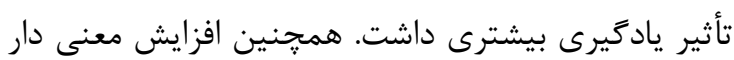

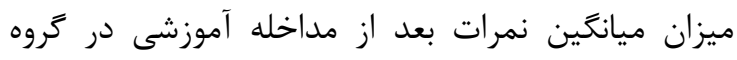
سخنرانى و جند رسانه ای، نشان دهنده ى تأثير مثبت آندان

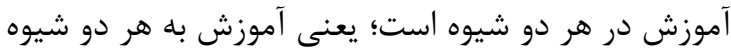

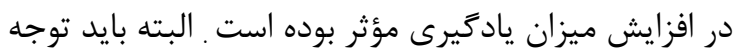

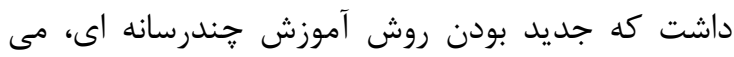
تواند موجب ايجاد اضطراب در دانشجويان شده و تأثير الثردي 
مى مانند. علت تفاوت در يافته هاى مطالعات مختلف ران مى توان در ماهيت دروس تدريس شده، شرايط مطالعه و مانف جامعه آمارى مورد استفاده دانست.

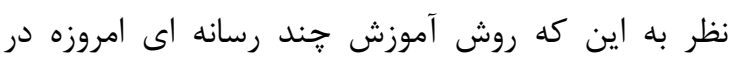
آموزش هاى مداوم و مادام- العمر به عنوان امرى مهمم و

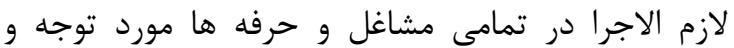

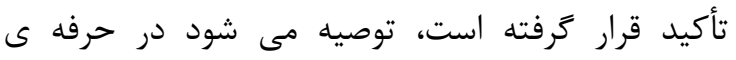

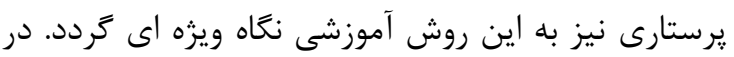
اين راستا تحقيقات نشان داده است كه روش آموزش جند آند

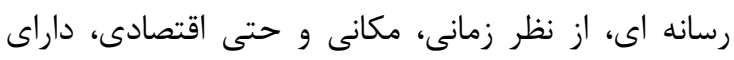

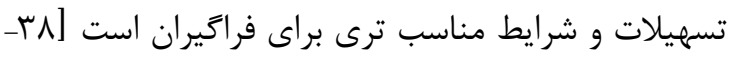
[F.

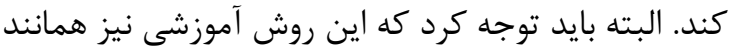

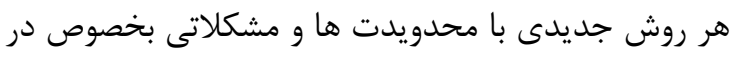

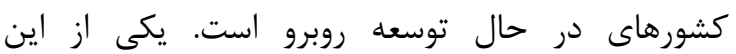
محدوديت ها را مى توان فقدان تعامل جهره به جال جهره

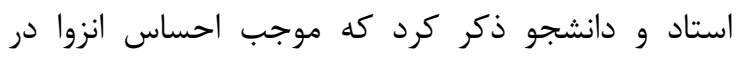

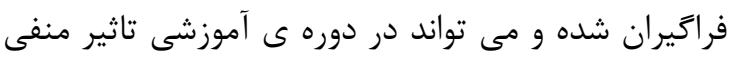

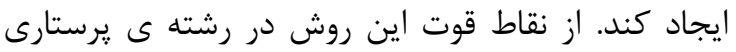

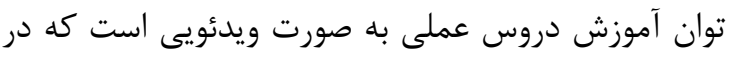

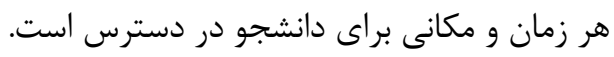

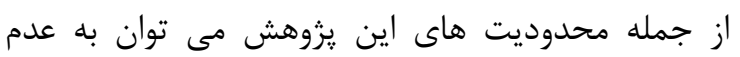
دقت دانشجويان در ياسخ گويى به سوالات مطالعه اشاره

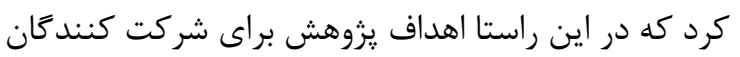
تشريح شد و وقت كافى در اختيار آنها قرار كرفت تا اين مشكل به حداقل برسد. همجنين هماهنكى جهت بركز كلاس و استفاده از اتاق انفورماتيك نيز با مشكلاتى همراه بود كه مديريت شدند.

\section{نتيجه گَيرى}

نتايج مطالعه نشان مى دهد كه هر دو روش آموزشى نرم

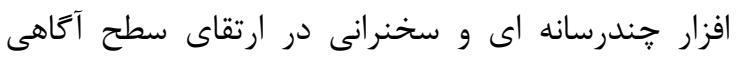

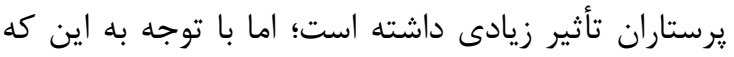
اين يزوهش نشان داد، فراخوانى اطلاعات آموخته شده به تهانه روش جندرسانه اى راحت تر و بهتر بوده و با توجه به درانه

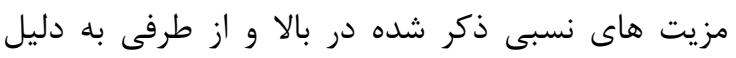

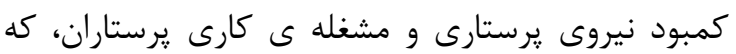
امكان حضور آنان در كلاس هاى سخنرانى را مشكل مى بـ ني
داشتند [rr]]. همجنين ميشل' در مطالعه خود نشان داد دانشجويانى كه از هر دو روش جهت يادكيرى استفاده مى دمى داندين كنند نسبت به دانشجويانى كه فقط مبتنى بر روش

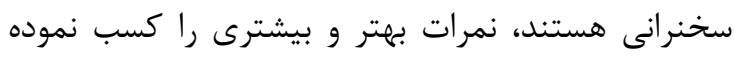
اند [FF]. درمطالعه ى استيسى كينى نيز كه آموزش لوله

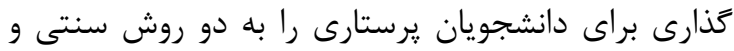

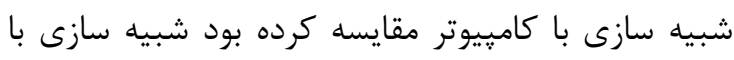

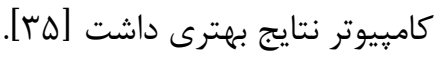
در تضاد با يافته هاى مطالعه ما، مطالعه شهسوارى و قزلباش به برترى آموزش سخنرانى نسبت به آموزش

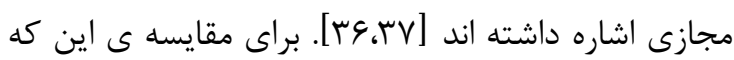
كدام روش آموزشى بهتر است كيلبرت اشاره مى كند كه آنه

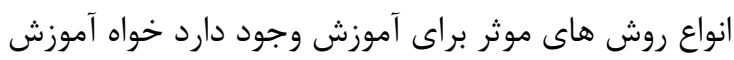

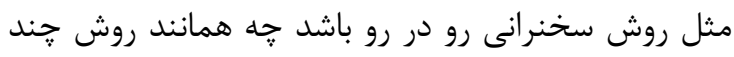

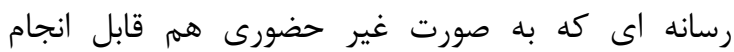

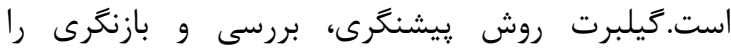

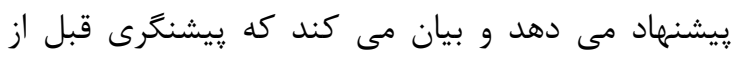
شروع دوره ى آموزشى بسيار اهميت دارد [عبـ دمان.

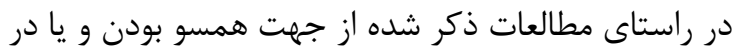

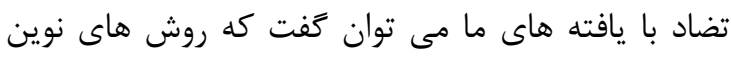

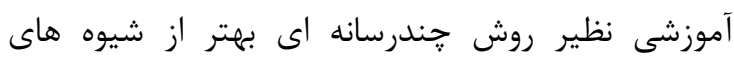

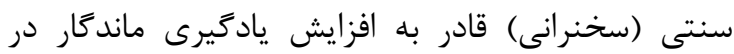

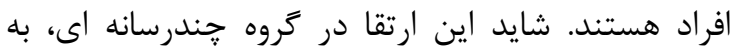

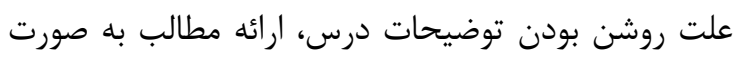

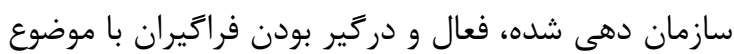

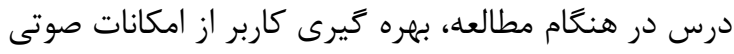

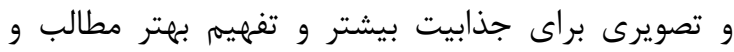

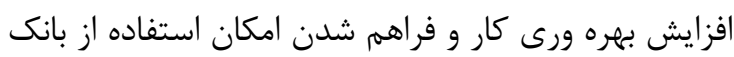
اطلاعاتى براى فراكير بوده است. اين كه در روش

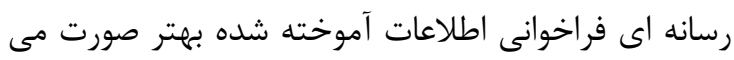

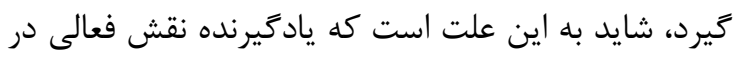

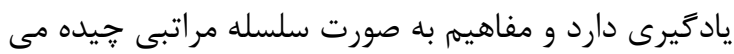
شوند، كه شباهت زيادى به نحوه جينش الطلاعات در

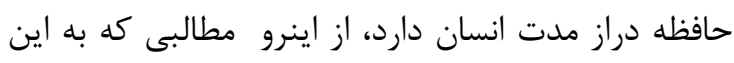

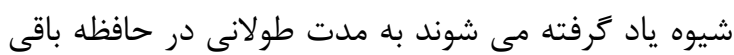

1-Mitchell 
اساس برنامه هاى آموزشى و حتى به عنوان تقويت كننده

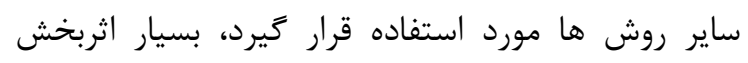

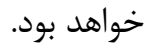
تشكر و قدردانى

اين مطالعه بر روى دانشجويان يرستارى دانش دانشكده

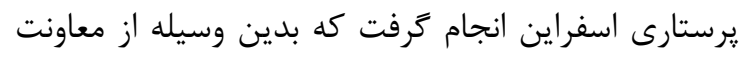
آموزشى يزوهشى دانشكده يرستارى اسفراين، كميته ى إنى

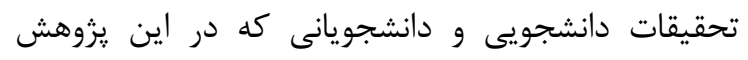
شركت داشتند سياسگزاريم.

\section{References}

1.Azer SA, Navigating Problem-Based learning, 1 st ed. Sydney: Churchill Livingstone; 2008.

2.Hassanpour Dehkordi A, Kheyri S., Shahrani M, The Effect of Teaching Using, Problem Base Learning and Lecture on Behavior, Attitude And Learning of Nursing (Bsc) Students, Shahrekord University of Medical Sciences Journal,2006;8(3):76-82,[Persian].

3.Beydoun MA, Wang Y, Do nutrition knowledge and beliefs modify the association of socio-economic factors and diet quality among US adults? Prev Med. 2008;46(2):145153.

4.Jukes M, Impact of early childhood health and nutrition on access to education in developing countries, Paediatrics and Child Health, 2007;17(12):485-491.

5.Bish B, Regis K, Gottesman MM, Educating parents about portion sizes for preschoolers, J pediatr Health care, 2005;19(1):54-59.

6.Bronte-Tinkew J, DeJong G, Children's nutrition in Jamaica: do household structure and household economic resources matter? Soc Sci Med. 2004;58(3):499-514.

7.Azizzi F, Education of medical sciences (challenges \& viewpoints). Tehran: The ministry of health and medical education; 2002[Persian].

8.Shabani H, Skills of Education, Tehran: SAMT; 2008,[Persian].

9.Salimi T, Shahbazi L, Mojahed S, Ahmadieh M, Dehghanpour M, Comparing the Effects of Lecture and Work in Small Groups on Nursing Students' Skills in Calculating Medication Dosage, IJME, 2007; 7. 84-79:(1) ,[Persian].

$$
\begin{aligned}
& \text { كند، آموزش يرستارى به روش خند رسانه اى به وسيله }
\end{aligned}
$$

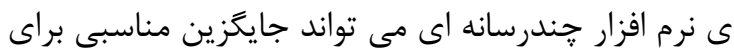

$$
\begin{aligned}
& \text { ساير شيوه هاى آموزشى كه مشكلات اجرايى دارند، باشدا. }
\end{aligned}
$$

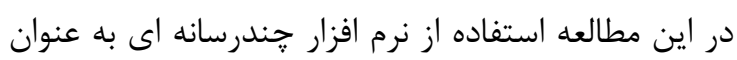

$$
\begin{aligned}
& \text { يك روش آموزش مهارت يرستارى، در دراز مدت باعث }
\end{aligned}
$$

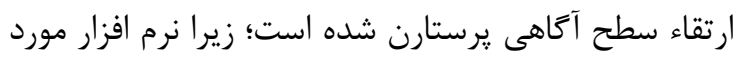

$$
\begin{aligned}
& \text { استفاده يك روش آموزش غيرمستقيم محسوب مئ شئ شود }
\end{aligned}
$$

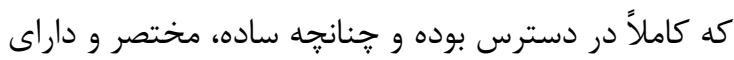

$$
\begin{aligned}
& \text { تصاوير خوبى باشد و بالاتر از همه اخر به عنوان يايه و داهن }
\end{aligned}
$$

10.Wright K, Student nurses need more than maths to improve their drug calculating skills, Nurse Educ Today, 2007;27(4):278-285.

11.Gabr H, Mohamed N ,Effect of ProblemBased Learning on Undergraduate Nursing Students Enrolled in Nursing Administration Course, International Journal of Academic Research,2011;3(1):154-162.

12.Docherty C, Hoy D, Topp H, Trinder K, Elearning techniques supporting problem-based learning in clinical simulation, Int $\mathrm{J}$ med inform, 2005;74(7-8):527-533.

13.Golshiri P, Sharifirad G, Baghernezhad F, Comparison of two methods of education (lecture and self learning) on knowledge and practice of mothers with under 3 year old children about growth monitoring and nutritional development stages, IJME. 2011;10 (5) :927-936,[Persian].

14.Mirshahzadeh N, Tootoonchi M, The Quality of Books, Questions and Teaching Method of Self-Learning in Continuing Medical Education: The Viewpoints of Selflearning Program's Participants in Isfahan University of Medical Sciences, IJME. 2007; 7(1):129-136,[Persian].

15.Khorami Rad A, Heidari A, Ahmari Tehran $\mathrm{H}$, Comparison of Two Self-Learning Methods(CD-Rom or Booklet) for Physician Education about Reporting Diseases Cases, IJME, 2011; 11 (2):149-158,[Persian].

16.Soleymanpour J, Skills of teaching and learning, Tehran: Ahsan; 2003.

17.Shaabani $\mathrm{H}$, Advance methodes of teaching ,Tehran: samt; 2005.

18.Pawlowski JM, Kozlov D, Analysis and Validation of Learning Technology Models, Standards and Specifications: The Reference Model Analysis Grid (RMAG), International 
Journal of IT Standards and Standardization Research.http://creativecommons.org/licenses/ byncsa/3,0/.

19.Khatoni A, Dehghan Nayery N, Ahmady F, Haghani H, The Effect of Web-Based and Traditional

Instructions on Nurses' Knowledge about AIDS , IJME 2011; 11 (2) :140-148. [Persian]

20. Saeedinejat S, Vafaeenajar A, The Effect of E-Learning on Students' Educational Success , IJME 2011;11 (1):1-9. [Persian]

21. Fesharaki M, Islami M, Moghimian M, Azarbarzin $M$, The Effect of Lecture in comparison with Lecture and Problem Based Learning on Nursing Students Self-Efficacy in Najafabad Islamic Azad University, IJME. 2010; 10 (3) :262-268. [Persian]

22. Emami Meybodi R, Dehghani Kh, Pourmovahed Z, Tavangar H, Knowledge and impact of two educational methods on speeches and pamphlets promoting awareness of high school students in Yazd to CPR, Rafsanjan Journal of Nursing and Midwifery. 2007; 2(4), 9-13 [Persian].

23.Khandan M, ELearning impact on type 2 diabetic patients self care centers of Kerman University of diabetes, Thesis MSc. 2008. Available from: www.irct.ir,[Persian].

24.Khakbazan Z, Jamshidi F, Abbass M, Damghanian M, Comparison of the effects of two teaching methods (lectures-training packages) on their knowledge about puberty health, Journal of Nursing Midwifery and science -life research 2008;14(1):418,[Persian].

25.Jabbari Byramy H,Bakhshian F, Comparison of two-person non-person training methods to prevent transmission of Obstetrics and Gynecology Outpatient units.Journal of Medical Research, Eighteenth year 2008;18(4):259-64,[Persian].

26.Zolfaghari M, Mehrdad N, Parsa Yekta Z, Salmani Barugh N, Bahrani N, The Effect of Lecture and E-learning Methods on Learning Mother and Child Health Course in Nursing Students, IJME, 2007; 7(1):31-39,[Persian]. 27.Unal Z, Comparative Study on Learning Outcomes of Web Based Vs. Classroom Based Instruction , Journal of College Teaching \& Learning. 2005;2(3):1-6.

28. Koch S, Townsend CD, Dooley KE, A case study comparison between web-based and traditional graduate level academic leadership instruction, Journal of Agricultural Education 2005; 46(4):72-82.

29.Hugenholtz NL, de Croon EM,Smits PB, van Dijk FJ, Nieuwenhuijsen K, Effectiveness of e-learning in continuing medical education for occupational physicians, Occup Med (Lond). 2008; 58(5): 370-372.

30.Wu PH,Kuo CH,Wu PL,Wu TH, Design a competence-based Networked Learning system: using sequence Control as Example, Current Development in Technology- Assisted Education (2006).

31.Green SM, Weaver M, Voegeli D, Fitzsimmons D, Knowels J, Harrison M, shephard K, The development and evaluation of use of a virtual learning development (Blackboard 5) to support the learning of prequalifying nursing students undertaking a human anatomy and physiology module, Nurse Educ Today 2006;26:388-395 .

32.Aggarwal R, Grantcharov T, Moorthy K, Hance y, Darzi A, Competency-based virtual reality training Curriculum For the acquisition of laparoscopic psychomotor Skill, Am J Surg. 2003;191:128-133.

33.Yom YH, Integration of internet-based learning and traditional face-to-face learning in an RN-BSN course in korea. Comput Inform Nurs. 2004;22:145-152.

34.Mitchell EA, Ryan A, Carson O, McCann $\mathrm{S}$, An exploratory study of web-enhanced learning in undergraduate nurse education, J Cclin Nurs. 2007;16:2287-2296.

35.Menchaca MP, Bekele TA, Learner and instructor identified success factors in distance education, Huston: Distance Education Publication; 2008;29(3): 231-52.

36.Shahsavari Esfahani S, Beigi P, Behin Aien N, Ayatollahi AR, Teaching Nursing Students about the Basic Principles of Infection Control: Programmed Instruction or Lecture Method ,Iranian Journal of Medical Education 2004;5(1): 2330,[Persian].

37.Qzelbash A, Atashzadeh F, Alavi Majd H, Yaghmaei F, Comparison of ECG correct reading learning method of problem solving and learning in lecture and tutorial method with computerized nursing students, Journal of- Nursing Research 2008; 3(11):715,[Persian].

38.Zareban E, Hydarnia AR, Rakhshan F , Jabbari H,Abdul Ghani, M, Investigate the 
effect of AIDS education program on knowledge, attitude and sailors Chabahar Port, Tabeb Shargh. 2006; 8(1):2936,[Persian].

39.Angvrany P, Keshavarz A, Sadrzadeh Y, Rahimi A, Effect of nutrition education booklets about breakfast on the knowledge of students in fourth grade six girls Tehran area. Medical Journal, 2007;65(2):49-53,[Persian].
40.Mohammadi B, Valizadeh S, Lak Dizaji S, The effect of education on knowledge, attitude and practice of nursing and midwifery teachers Tabriz University of Medical Sciences in the field of clinical teaching behaviors.Iranian Journal of Medical Education third year , 2003;2(0):1011,[Persian]. 
Original Article

\title{
Comparing the Effect of Education by Lecture and Multimedia Software on Learning of Fundamental of nursing in nursing students
}

\author{
Mollazadeh $H^{l}$ ، Kameli $A^{2}$ ، Jafari chogan $M^{1}$ ، Mirhosseini $F^{l}$, SHoja $M^{3 *}$
}

${ }^{1}$ nursing student, Nursing faculty of Esfarayen, North Khorasan University of Medical Sciences, Bojnurd, Iran

${ }^{2}$ M.Sc. of nursing, North Khorasan University of Medical Sciences, Bojnurd, Iran

${ }^{3}$ M.Sc. of Epidemiology, Nursing faculty of Esfarayen, North Khorasan University of Medical Sciences, Bojnurd, Iran

\author{
*Corresponding Author: \\ North Khorasan University of \\ Medical Sciences, Nursing \\ faculty of Esfarayen \\ Email: \\ mohsenshoja61@yahoo.com
}

\begin{abstract}
Background \& Objectives: According to the important role of nurses, it is required to apply proper learning techniques for education of theoretical and practical skills for nursing students. Therefore this study aimed to compare the effects of tow methods including lecture and multimedia learning in learning of fundamental of nursing in nursing students.

Material \& Methods: This study was conducted on 50 nursing students of nursing faculty of Esfarayen-2012. Samples were randomly divided into two groups (lecture teaching methods and teaching multimedia groups) and were trained. They were examined before and after the intervention and another test (remember) were done after 4 weeks. Data were analyzed by SPSS18 statistical software.

Results: Pre-test mean scores were significantly different with post-test and remember stage in two educational groups $(p<0 / 001)$. Post-test mean scores of two groups was not significantly different, but in remember stage Multimedia training group had better mean $(p<0 / 05)$. Both methods had the effect on student learning, but the effect of multimedia training method was more enduring over time.

Conclusion: our results showed multimedia education method has more lasting effects than lecture education method. It is hoped that this method is more widely implemented with other methods to training nursing students.

Key words: fundamentals of nursing, learning, lecture, nursing, multimedia
\end{abstract}

Submitted:25 Nov 2013

Revised:5 Feb 2014

Accepted:26 May 2014 